infirm and other special cases.

The publicity given to research projects that are plainly outrageous has, however, tended to overshadow some of the more delicately balanced arguments and concerns. For example, what controls should be applied to research on children who lack not only the legal capacity to give their consent to take part but who may also be unable to understand the possible risks? Another area fraught with difficulty is research on prisoners-for example, is a man who is denied basic freedoms and who is continuously subject to the will of prison authorities truly free to give his consent to anything? Moreover, does the opportunity to take part in a research project which will relieve the routine of prison life and which may involve other large rewards carry undue incentives which, to him, outweigh the risks? (More than $70 \%$ of preliminary human testing of drugs in the United States is carried out on prisoners.) Equally difficult questions are raised in connection with research on the mentally retarded, on foetuses and on pregnant women.

It was those tricky questions that were faced by the ad hoc NIH committee, whose recommendations were published last week in the Federal Register. The committee believes that controls on such research should be greatly strengthened at both the federal level and in the institution in which the experiments will be conducted and it also suggests a few cases in which human experimentation should be outlawed entirely.

As far as research on children is concerned, the committee suggests that any proposal should be reviewed for ethical considerations by at least three committees, two of which would be in the institution in which the research is to be carried out and one in the agency sponsoring the research. It would work like this. Before submitting a proposal to $\mathrm{HEW}$ for funding, the project must be reviewed by an Organisational Review Committce, consisting of members drawn from a variety of disciplines, some of whom would not be employed by the institution concerned. Once the committee has approved the experimental procedures, the proposal would then be sent to HEW, where it would be subjected to the usual peer review system for scientific merit. The next stage is review by special committees to be established in every agency of HEW. These Ethical Review Boards would again consist of members from various disciplines and, as well as examining individual projects, they would advise the agency on general ethical issues.

Once approved by this process, the project would then come under the supervision of yet another institutional review committee, the Protection Com- mittee. Its duties would be to ensure that those who take part in the experiment are fully informed of the risks, and that their consent and that of their parents is freely given. The Protection Committee would also be on hand to make sure that participants could pull out at any stage if they so wished.

In addition to that mechanism, the committee also suggests a number of other criteria that should be met before research can be carried out on children. First, the consent of both parents should be obtained. Second, the consent of any child over the age of seven who takes part in an experiment should be obtained. Finally, children without natural or adoptive parents, or those detained in an institution or in court, should be excluded from participating.

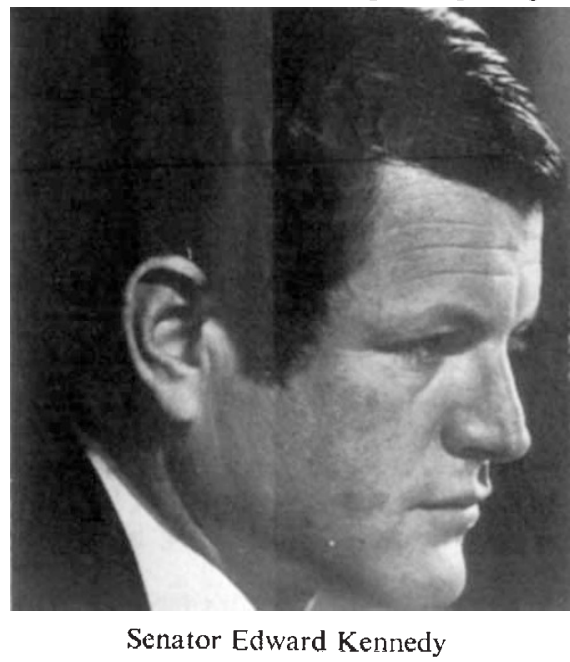

As for research on prisoners, the committee notes that it is ultimately up to the courts to decide whether prisoners are in a position to give consent without undue coercion, but it points out that in the meantime HEW should adopt a set of regulations which afford prisoners as much protection as possible. In short, the committee suggests that a project involving prisoners should come under the purview of a Protection Committee consisting of at least five members, one of whom would be a prisoner. It would make sure that those who take part are given full information and that they are not offered undue incentives.

Finally, the committee suggests that research should be carried out on the mentally infirm only if it can be proved that the study cannot be accomplished with the use of other volunteers; that no research should be performed on the abortus if it involves prolonging the heartbeat and respiration or, conversely, if it will of itself terminate the heartbeat; and that no research involving implantation of human ova which have been fertilised in vitro shall take place until animal studies have indicated that it would be safe (and that includes studies of the naturally born offspring of the products of in vitro fertilisation).

\section{MORE ON MEDICAL ETHICS}

\section{... But Britain Differs}

Clinical research investigations of children and mentally handicapped people should be allowed, according to a committee of the Royal College of Physicians. In a report published today on the Supervision of the Ethics of Clinical Research Investigation in Institutions ( $£ 0.10$ from the Royal College) the committee says that to ensure advances in medical treatment research must continue, even though the investigations might not be of direct benefit to the patient.

The committee adds, however, that the investigation should be carried out "only when the procedures entail negligible risk or discomfort and subject to the provisions of any common, or statute, law prevailing at the time".

The Royal College document is in sharp contrast to the report of the ad hoc committee of members of the National Institutes of Health, the National Institute of Mental Health and the Food and Drug Administration published last week in the United States (see page 239). The report from the United States, which is likely to be incorporated into firm proposals by the Department of Health Education and Welfare, recommends much more stringent controls on clinical research than does that from the Royal College.

The Royal College report is a sequel to one published by the same body in 1967. Sir George Godber, Chief Medical Officer at the Department of Health and Social Security (DHSS), wrote to the late Lord Rosenheim, then president of the college, in 1971 asking him to investigate further the supervision of the ethics of clinical research in institutions. In particular, Sir George asked advice about the composition of ethical committees and the scope of clinical investigations.

The advice now given to the DHSS is that ethical committees should be small and should be constituted so that they do not "cause an unreasonable hindrance to the advancement of medical knowledge". The members should be experienced clinicians but there should also be one lay member. The committee stresses that this lay member must be someone "who is not associated with the [medical] profession in any par'dmedical activity". Biochemists and psychelogists are therefore ruled out.

In view of the uncertainty about the procedures which have to be referred for approval, the Royal College advises that application should be made to an ethical committee "for all proposed clinical research investigations". The committee stresses the fact that a drug which has been granted a Clinical Trial Certificate or a Product Licence by a Licensing Authority on the recommend- 
ation of the Committee on Safety of Medicines "in no way absolves the ethical committee from investigating the ethical aspects of that trial".

Patients who are undergoing tests which are not intended for their benefit should be given a full explanation of the proposed procedure and the patient should feel free to withdraw from the tests at any time, says the committee. Except for trivial procedures of which venapuncture is an example, an explanation of the procedure should be given in the presence of a witness.

When the research is intended for the benefit of the patient the committee feels that there are circumstances in which it would be "inappropriate or even inhumane" to give detailed explanations of the procedures involved. Such cases should be investigated with particular care by the appropriate ethical committee.

\section{SOVIET SCIENCE}

\section{Land and Sea}

LUNOKHOD-2, which landed on January 16,1973 , in the Le Monnier crater on the eastern edge of Mare Serenitatis, had a region of particular selenological interest to explore-the transition from mare to highland. Operating among features assigned unofficial working names such as 'Head-on Hills', 'Shallow Crater', 'Round Bay', 'Near Cape', 'Far Cape' and 'Straight Rille', the Lunokhod recorded and transmitted data of considerable significance, not only to the interpretation of this specific type of area but to lunar research as a whole.

One of the most important experiments of Lunokhod-2 was the determination of possible changes in chemical composition of the transition area surface. A modified version of the RIFMA X-ray spectrograph used on Lunokhod-1 was used-the new instrument, RIFMA-M, being specifically adapted to determining the ratio of iron to other elements -notably aluminium and titanium. Near the landing site, on the slope of a crater of diameter $40 \mathrm{~m}$, readings of $\mathrm{Si}, 24 \pm 4 \% ; \mathrm{Ca}, 8 \pm 1 \%$; $\mathrm{Fe}, 6 \pm 0.6 \%$; and $\mathrm{Al}, 9 \pm 1 \%$ were obtained. (The iron reading obtained by Lunokhod-1 for Mare Imbrium was 10 to $12 \%$.) As Lunokhod-2 moved southwards, towards the 'Head-on Hills' on the edge of the highland, no significant changes were at first observed-data from a $13 \mathrm{~m}$ diameter crater at approximately $1.5 \mathrm{~km}$ from the landing site were close to the first readings. But as it moved closer to the hills the iron content.decreased and $5 \mathrm{~km}$ from the landing site it had fallen to $4.9 \pm 4 \%$. On February 19 a minimum reading of $4.0 \pm 0.4 \%$ was obtained. During this part of the survey, the aluminium content increased to $11.5 \pm 1.0 \%$. Writing in Pravda (November 20, 1973), Academician A. Vinogradov and Dr S. Solokhov attribute this change to a general variation in regolith composition in mare-to-highland transitions.

Panoramic television surveying of the transitional region revealed a number of interesting features, including a crater of diameter 15 to $20 \mathrm{~m}$ in the neighbourhood of the 'Head-on Hills' with associated slip terraces of some 10 to $15 \mathrm{~m}$. In this region the density of small craters (diameter 2 to $3 \mathrm{~m}$ ) fell to one half to one third of the average maria density.

A particular object of investigation was the 'Straight Rille', which stretches for some 15 to $16 \mathrm{~km}$ in a north-south direction along the south-east edge of Le Monnier. On both the eastern and western edges of the rille, a 30 to $40 \mathrm{~m}$ zone of intensive shear towards the fault was observed. The thickness of the regolith decreased as the lunokhod approached the rille and the lip consisted of a rock 'border' with boulders of diameter at least 1 to $2 \mathrm{~m}$.

One interesting feature of the Lunokhod-2 programme was an attempt to correlate chemical composition to visual observation of the albedo. Using photometic telephotography from Earth and the RIFMA-M observations, a general relationship between the readings has been established. This is a result which is considered by the Soviet team to "extend considerably the significance of the Lunokhod-2 results".

The magnetometer experiments, a new feature of Lunokhod-2, revealed some characteristic variations in the field attributed to induction currents produced by variations in the interplanetary field. These data, it is claimed, should reveal the conductivity of the Moon to a depth of some hundreds of kilometres.

\section{NUCLEAR WEAPONS \\ Poor Security}

by our Washington Correspondent

LAST month, when fighting in the Middle East ras at its peak, the United States Atomic Energy Commission (AEC) ordered security to be stepped up at all institutions which handle enriched uranium and plutonium, to ensure that none of the material could be stolen and end up as part of a nuclear finale to the Arab-Israeli conflict. The extra precautions were, it seems, more than justified, for a recent investigation by the General Accounting Office (GAO) has come up with the disturbing finding that security arrangements in some plants which hold strategic nuclear materials would pose few problems for a hamfisted amateur burglar, let alone a terrorist organisation.

The most expensive, lengthy and diffi- cult part of making a nuclear weapon is the production of fissionable material, but fabrication of the weapon itself is reckoned to be a relatively easy task which would not be beyond the wit of scientists in most countries. Thus, if a supply of enriched uranium or plutonium could be diverted from installations in the United States, probably over a period of time, nuclear weapons could be within reach of those willing to pay the price. A crude bomb, such as the ones dropped on Hiroshima or Nagasaki, would require some $17 \mathrm{~kg}$ of enriched uranium or about $6 \mathrm{~kg}$ of plutonium, and it would, of course, take only one such bomb-or the threat of it - to upset the military balance in the Middle East.

The AEC itself acknowledged such risks in an internal report in 1971, which came to the conclusion that "as long as significant quantities of nuclear materials are in active use by the government, by government contractors, and by licensed commercial and other interests, there will be a distinct probability that some of those materials will be stolen, unexplainably or accidentally lost, diverted from authorised use, or used or disposed of in unauthorised ways".

With such considerations in mind the GAO, which carries out investigations for Congress, inspected the security arrangements in three plants which hold strategically important quantities of special nuclear material (as enriched uranium and plutonium are called). It found that in two of the plants, security "was so limited that protection was inadequate".

This is what the GAO found at one of the plants which, mercifully, remained nameless. The plant was protected by a part-time security officer and four armed guards, one of whom was on duty at all times, and it was surrounded by an 8 -foot high wire fence. Special nuclear material, some of which is described in the report as being "of high strategic importance", was located in three buildings just inside the fence. Entrances to the building were connected to an alarm system.

On the face of things, that seems a fairly good security system, but the GAO found that it had the following defects :

- The fence had thirteen weaknesses, ranging from broken welds to inoperative locks, which would allow it to be breached with ease. Ten of the weaknesses were out of sight of the guard post.

- One of the storage areas was a prefabricated structure, just 16 foot from the fence, made from sheet steel panels 3 foot by 9 foot. According to the GAO investigators, who tested the strength of the panels with an adjustable spanner, "within 1 minute we were able to remove five metal screws from 